Goldschmidt 2021 Abstract

https://doi.org/10.7185/gold2021.6019

\section{Xenon behavior in deep crust}

QI CHEN ${ }^{1}$, CHRYSTÈLE SANLOUP ${ }^{2}$, HÉLÈNE BUREAU ${ }^{3}$, KONSTANTIN GLAZYRIN ${ }^{4}$ AND ROBERT FARLA ${ }^{4}$

${ }^{1}$ IMPMC, Sorbonne Université

${ }^{2}$ Institut de minéralogie, de physique des matériaux et de cosmochimie (IMPMC) - CNRS

${ }^{3}$ IMPMC

${ }^{4}$ Deutsches Elektronen-Synchrotron

Presenting Author: qi.chen@upmc.fr

Xenon has long been taken as a tracer of the evolution of the Earth and formation of the Moon ${ }^{[1]}$. Compared to other noble gases, up to $90 \%$ Earth and Mars' $\mathrm{Xe}$ is missing from the atmosphere, known as the 'missing Xe paradox ${ }^{\text {[2] }}$. Recently many studies support $\mathrm{Xe}$ reactivity at depth with planetary materials ${ }^{[3][4]}$. To better constrain Xe distribution, one of the most effective way is to investigate the partition coefficients of the major silicate minerals and melts in melting and crystallizing processes. Experiments from quenched methods find Xe partly located in gas bubbles, resulting in inconsistencies in $\mathrm{Xe}$ solubility and partition coefficients whether or not bubbles are analyzed ${ }^{[5][6]}$. Therefore, it is questionable whether the measured solubility and partition coefficient faithfully reflects the equilibrium solubility and partition coefficient at experimental conditions. We hence combine two in-situ methods to investigate partitioning of Xe in magma/mineral system using (1) Resistance diamond anvil cell with in-situ Synchrotron X-ray Diffraction and X-ray fluorescence Analysis; (2) large volume press with insitu Synchrotron Energy Dispersive X-ray Diffraction Analysis under high $P$ and high $T$ up to $3 \mathrm{GPa}, 1050{ }^{\circ} \mathrm{C}$. Xe-doped hydrous plagioclases are used as starting glass. We find that $\mathrm{Xe}$ becomes pretty compatible at high $P-T$ conditions (Fig. 1), indicating $\mathrm{Xe}$ is preferentially retained in minerals during continental crust partial melting processes. Our result strongly supports the hypothesis of Xe storage at depth to explain the 'missing Xe' paradox.

[1] Ozima \& Podosek (1999), Journal of Geophysical Research: Solid Earth, 104(B11), 25493-25499. [2] Anders \& Owen (1977), Science, 198(4316), 453-465. [3] Sanloup et al. (2005), Science, 310(5751), 1174-1177. [4] Leroyet al. (2018), Earth and Planetary Science Letters, 484, 103-110. [5] Heber et al. (2007), Geochimica et Cosmochimica Acta, 71(4), 10411061. [6] Hiyagon \& Ozima (1986), Geochimica et Cosmochimica Acta, 50(9), 2045-2057.

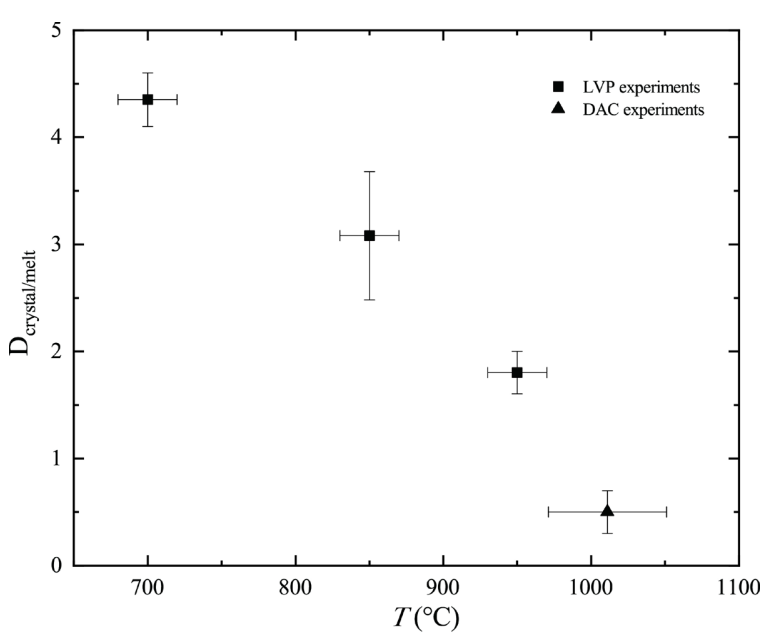

Fig. 1: Partition coefficients of Xe between plagioclase and melt at high $T$. 